\title{
The Current Crisis of Higher Education and Corresponding Countermeasures of Academic Disciplines
}

\begin{abstract}
Zhanwen Chen
School of Humanities and Journalism, Xiamen University Tan Kah Kee College, Xiamen, Fujian 363105, China

*Corresponding author. Email: pam19035@stu.xujc.com

ABSTRACT

China's higher education has developed for several decades since its establishment. Although numerous achievements have been made, it is still facing huge crisis, which can be specifically summarized as discipline construction and survival crisis. It requires reasonable theory construction and development as guidance to help it avoid and respond to the crisis. In this regard, from the perspective of disciplines, this article summarizes in detail the causes for the crisis faced by higher education disciplines, clearly points out the categories of current crisis core, and proposes countermeasures including the improvement of discipline construction and re-scientization. Facing the development issues concerning higher education at this stage, relevant educators and researchers need to continuously reform and innovate, establish a harmonious modern higher education system, specify social attributes and education goals, and assist the development and upgrading of higher education disciplines.
\end{abstract}

Keywords: Higher Education, Disciplinary Planning, Education

\section{INTRODUCTION}

Since the Reform and opening up policy, especially in the last ten years. Our country's higher education has made great progress. At the same time, a series of crises and contradictions have inevitably occurred, especially the development issues from the perspective of disciplines, which have limited further upgrading of our country's higher education. Therefore, how to treat and analyze our country's current and future higher education, effectively prevent the education crisis, and propose appropriate countermeasures, is an important task for our country in higher education at this stage[1].

The Chinese government has consistently attached great importance to higher education, and has formulated and planned a series of education development policies in accordance with the national conditions. Its core items mainly include the following aspects: First, scale development. The National Bureau of Education proposed that scale development is the key to identify the progress level of higher education in our country. High subjective education quality and subject scientific research quality need to be established on the basis of a certain educational scale, and there is no such thing as "quality" without the "quantity" of education.
The development of our country requires high-quality talents, and higher education shoulders heavy responsibilities of cultivating advanced talents[2-3]. In 2017, the State Council approved the Report on Accelerating the Development of Higher Education proposed by the Ministry of Education, which clearly stated that in order to effectively realize the goals suggested in the national construction programs proposed by the Communist Party of China, a large number of high-quality talents are needed in various regions. There is an urgent need for the national education department to cultivate more talents at an early time. Accelerating the development of higher education disciplines has become a priority for national development. Apart from scale development, classification development is also required. From the perspective of sociology and pedagogy, the development of higher education is required to combine the needs of social and economic development, so as to make sure both are coordinated and thus gain win-win results. The current social structure of our country is relatively complicated, and the demand for education talents is tending to be constantly diversified. It can be said that diversification has become the core feature of the development of higher education in our country. 
Therefore, the relevant education departments have proposed that our country's higher education should adhere to the classification development and guidance. In response, our government departments have also proposed a series of measures. Since the 1990s, a large number of higher vocational colleges have been established in China, which has greatly enriched the disciplines of domestic higher education. In February 2014, the State Council issued a deployment strategy which "guides a group of application-oriented universities to transform into technology-oriented ones," and stipulated the requirements for the development of higher education. The last is the key development. Key development means promoting work in all areas by drawing upon the experience gained on key points, so as to fasten the development pace of our country's higher education, including the level of schooling. In order to cater to international needs, our country has proposed a series of major measures early on, including building world-class universities and education discipline strategies, concentrating national financial resources, and focusing on building a number of high-quality universities. In addition, the key development also includes characteristic development. Our country has put forward the China Education Reform and Development Program which clearly state that China needs to formulate classification standards and policy measures for higher education institutions, clarify the needs and characteristics of different institutions, so as to achieve educational innovation[4].

With the constant deepening of our country's higher education reform, China's higher education disciplines are becoming more independent and mature. However, with the increasing social environmental need, our country's higher education is bound to effectively and properly handle the problems regarding disciplines, academics, academic construction, students, etc. in the midst of a new educational environment. Only when we actively respond to crises can China realize the normal development of higher education.

\section{THE CAUSES FOR THE CRISIS OF HIGHER EDUCATION}

Although our country's higher education has undergone years of construction and development, it is fundamentally a relatively young developmental discipline. Therefore, construction issues concerning higher education have always been the key factors needed to be considered in the development of higher education in our country, and at the same time the future development path of higher education is needed to be discussed[5-6]. In August 2016, scholars specializing in related fields of higher education in our country held an important disciplinary education seminar at Xiamen University. The meeting focused on the development of higher education in our country and agreed upon the outline for future development, which was called the Xiamen Consensus. The "Consensus" clarified the fundamental tasks of our country's current higher education discipline construction and future adjustment strategies, especially the crisis facing our country's higher education disciplines, and finally made a conclusion in detailed.

\subsection{Crisis is the Inherent Development Situation of Humanities Disciplines}

From a global perspective, "crisis" is a common problem encountered by all social and humanities disciplines. The emergence of a crisis does not often lead to the end of the discipline. On the contrary, it promotes the educational reflection and reform of the discipline to a large extent, thereby promoting disciplinary progress. For example, philosophy, knew as the mother of science, has encountered crises many times during its development process, and each crisis will encourage the development and reform of the discipline of philosophy. Among them, the so-called development of philosophical epistemology, the reform of philosophical language theory, and the reform of ethics are relatively famous. Philosophy under the crisis has met countless opportunities, but today's philosophy is facing the dilemma of "losing unique research objects". It has also promoted new development concepts such as "returning to life, moving toward reality, and paying attention to ethics", making traditional philosophical disciplines take on new missions during the "crisis".

Another example is that the development of modern electronic media and the Internet has impacted traditional literary disciplines. Many literary researchers believe that the proliferation of network image data will detonate "aesthetic popularization and proliferation", thereby disrupting literature's esthetic attention itself. But the reality is the opposite. The development of network multimedia has injected new development connotations to the literary disciplines. Relying on various platforms, literary readers and authors have come closer together, and the research of literary disciplines has also been deepened. From a series of examples, it can be seen that the current crisis in the development of higher education in our country is somehow valuable. On the contrary, it will motivate us to make educational reflections, and it can also spur relevant education researchers to continuously expand new educational paths.

\subsection{The Inevitable Limitations of "System Dependency"}

Our country's higher education has a history of several decades. Although many years of development have produced countless educational achievements, 
there also exist many problems. In recent years, some unreasonable institutional arrangements of domestic education disciplines have caused the independence of higher education disciplines to be in jeopardy. Many colleges and universities do not even endow higher education with an independent educational research direction. In particular, the "Double First Class" initiative proposed for the development of the current domestic education has triggered large-scale adjustments and reforms of educational institutions, and has led to various divergences in the division of educational disciplines.

Compared with the traditional and mature education disciplines, the disciplinary crisis of higher education has distinct characteristics: the crisis of traditional disciplines is generally the crisis in the field of knowledge, that is, the crisis of theory and methodology. The higher education discipline exists not only this theoretical and methodological crisis, but also hidden dangers in the external system. The so-called system hazards are issues that we often discuss about, such as the status of disciplines, institutional personnel, and the division of degree points. The current domestic higher education crisis mainly comes from these respects, many of which are contradictions caused by its internal development. It can be said that the current crisis of higher education disciplines is an obvious existential crisis. There are serious unreasonable systems and human policy interventions, which are also caused by the limitations of institutional disciplines. Different from mature disciplines, the higher education system is highly dependent and is obviously impacted by the system. This is also the core of the frequent crises of this discipline.

\section{THE DIVISION OF THE CRISIS OF CONTEMPORARY HIGHER EDUCATION}

From the actual situation, the crisis faced by higher education in our country is mainly consisted of two different types, or a combination of two forms. One is the institutional crisis of disciplines in a broad sense, which is related to the "institutional dependency" mentioned above, and is mainly affected by the national system and closely related to the development of higher education itself; the other is the inherent survival crisis of disciplines. However, current domestic higher education manifests the "resonance" state of the disciplinary crisis. Therefore, it is an urgent need to conduct more detailed analysis and make improvements on the basis of a correct understanding of the crisis.

\subsection{Crisis Occurred in the Discipline Construction}

Higher education in our country at this stage is still dominated by the national discipline system, which includes the classification and approval of disciplines. The process is as follows: first, the country needs to rigidly classify disciplines, and then formulate related discipline catalogues. The discipline construction and student training of major domestic universities must pass the examination and approval of the discipline catalog to obtain national approval and subsidies, be incorporated in the discipline catalog system, and obtain the discipline construction and the funds, officially budgeted posts and teacher education provided by the state. It can be said that the various disciplines of domestic education cannot be separated from the scope of the national education catalog. In contrast, in Western countries such as the United States, the establishment of disciplines does not require national approval, but is jointly decided by the national education and academic bodies, and the state is only responsible for supervision and statistics analysis. It can be seen from this that our country's discipline system is characterized by strong institutional rigidity in the establishment and development management. This can indeed increase the rigor of education, but it also reduces the diversified development of education to a certain extent.

In this context, our country's disciplinary education has shown strong subject dependence. Since the 1980s, the establishment of higher education disciplines in our country requires the approval of the State Council to obtain the discipline construction, instead of its own mature knowledge system. For higher education, it is precisely because of the support of the national system that it can make up for the shortcomings of its own discipline construction to a certain extent. It can be said that there is no current higher education without the guarantee of the national discipline system. So looking back at the crisis facing our country's higher education, not only the internal cause of the languishing development of its own knowledge system, but also the external cause of the adjustment of the policies of the national discipline system. In 2011, the National Education Commission of our country obeyed the opinions of the State Council and revised the discipline catalog. The second-level disciplines were canceled as a whole, and the evaluation of all discipline constructions was carried out in accordance with the first-level disciplines. Many disciplines have lost opportunities for educational evaluation, and at the same time reduced their access to national resource subsidies. Higher education, as a non-normal university discipline, has been severely hit and faced enormous challenges.

\subsection{Crisis in the Discipline Survival}

Throughout the history of the development of higher education in our country, it can be seen that in the course of decades of development, it has confronted with countless crises, which are mostly developmental. However, the current higher education disciplines are 
facing survival crises, which can be subdivided into two aspects:

The first is the overflow of the national postgraduate training discipline catalog. Our country's discipline catalog is essentially a supervisory policy used to regulate the development of the degree system. But at this stage it also undertakes the tasks of discipline evaluation and resource allocation statistics. At this stage, our country's subject catalog has overflowed, and the subject catalog itself can be used to distinguish school types and affect the establishment of colleges and departments, so it exerted severe impact on higher education. Second, our country's current disciplinary system has been obviously influenced by the "unit", which has formed the dual affiliation (academic and unit affiliation) of university teachers. It is difficult to gather all the talents for academic exchanges in a short period of time. Under the dual impact of spillover effects and unit ownership, our country's higher education disciplines are prone to changes in the nature and functions of the disciplines and institutions, so there are survival crises.

\section{RESPONSES TO THE CRISIS OF CONTEMPORARY HIGHER EDUCATION}

In the face of various crises of higher education, how to face and tackle the crisis is a problem that our country's higher education needs to attach great importance to. In this regard, I propose the following several points:

\subsection{Adherence to the Correct and Scientific Development Direction}

In the development of higher education disciplines in our country, there have always been disputes between disciplines and research theories. Some educators believe that the enrichment of higher education professional disciplines can improve their educational status, while others hold that higher education disciplines should exist in the field of research. Therefore, for the future development of higher education disciplines, we must first plan the development direction of discipline education. From the perspective of disciplines, re-examine the disciplines of higher education and redefine higher education with classic discipline standards. That is to transform traditional classic disciplines into modern ones. The two disciplines are different in essence. On the one hand, the so-called classical disciplines are based on the evolutionary laws of knowledge logic. Theoretical disciplines they established generally reflect a tree structure and follow a strict knowledge development path. On the other hand, the modern discipline is a comprehensive and interdisciplinary discipline established with the socialization development as guidance and the key objectives of solving social problems. However, the higher education at this stage is obviously more suitable for the development of social disciplines.

\section{2. "Re-scientization" of Disciplines}

In view of the current disciplinary crisis, adhering to the correct direction of scientific development is only a prerequisite. It is also necessary to take the motivation of the crisis into consideration and start from the level of zero discipline construction to achieve the re-scientization of disciplines. This exists in two issues: one is that the research structure of higher education must be reset. Because the disciplines and units in our country are interconnected, which has resulted in the current status quo of unit management disciplines. If there is no suitable unit leader, then the study of higher education disciplines will become empty talk; the other is that higher education needs to obtain a first-class discipline construction status. At present, some experts and scholars of higher education lack confidence in striving for the status of higher education as a first-class discipline. In this regard, relevant education researchers need to continuously consolidate the social nature of higher education disciplines, so as to improve educational cognition and gain better results, as well as tilt towards higher-quality disciplinary resources.

\subsection{Upgrade of Knowledge Form}

Whether higher education can become an important educational discipline depends not only on policy support, but also requires continuous upgrading of its own educational knowledge system. Needless to say, the subject content system of higher education in our country remains imperfect. This requires relevant educators to raise their academic awareness, continuously develop core knowledge of education subjects, and promote the upgrading and scientificization of the disciplinary education system. Only by upgrading their own education can they enhance the status of education fundamentally.

\section{CONCLUSION}

In summary, although our country's higher education disciplines are faced with a huge crisis, there are also development opportunities coming out of it. The regional characteristics of the development of higher education are relatively obvious in our country, so the development issues concerning higher education in different regions are quite different. But they stick to the same paths to development. Therefore, in order to effectively promote the coordinated development of higher education, it is necessary to continuously enhance the cognition of the disciplines, and at the same time seriously think about how to realize 
interdisciplinary achievements, continuously improve the efficiency of discipline education management from content organization to personnel training, and promote disciplinary exchanges. Only in this way can we respond reasonably to crisis, and constantly increase the level of discipline construction in higher education.

\section{REFERENCES}

[1] Gao Yingying. The Current Crisis of Higher Education and its Solutions[J]. Literature Education, 2018, 000(002):153-154.

[2] Chen Ming, Wang Chunchun. Questions from Qian Xuesen: Four Puzzles of the "Sphynx Mystery" in Higher Education[J]. 2021(2017-4):16-19.

[3] Li Jun. Higher Education as a First-Class Discipline_-Based on the Perspective of
Disciplinary Policy and Discipline History[J]. Higher Education Research, 2011(11):32-37.

[4] Wang Shenglan. The Evolution and Direction of Research Methodology of Higher Education in my country: From the Perspective of Disciplinary Paradigm Shift[J]. Collection of Modern Education, 2019, 000(005): 49-57.

[5] Liu Xiaoqiang. Disciplinary Construction: a Meta-perspective Investigation_-Reflections on the Discipline Construction of Higher Education [J]. Higher Education Research, 2011, 000(006): $10-10$.

[6] Liu Xiaoqiang, Pan Maoyuan. Disciplinary Construction: a Meta-perspective Investigation-Reflections on the Discipline Construction of Higher Education[J]. Higher Education Research, 2011(6): 10-10. 